\title{
Smiley Faces: The Evaluation of Watches as a Function of the Time Displayed
}

\author{
Adrian Furnham1,2, James King1, Vladimir Kolzeev1 \\ ${ }^{1}$ Department of Psychology, University College London, London, UK \\ ${ }^{2}$ Norwegian Business School, Olso, Norway \\ Email: a.furmham@ucl.ac.uk
}

Received 13 September 2015; accepted 8 November 2015; published 11 November 2015

Copyright (C) 2015 by authors and Scientific Research Publishing Inc.

This work is licensed under the Creative Commons Attribution International License (CC BY). http://creativecommons.org/licenses/by/4.0/

(c) (i) Open Access

\begin{abstract}
Wristwatch advertisements show a preference for having the watch hands displaying the time 1:50 or 10:10 which suggest a "smiley face". This paper reports two studies, one with students, the other with non-students. Participants rated six different watches showing six times on four different scales: perceived attractiveness, expensiveness, the income level of the typical wearer of the watch, and the sense of style of the typical wearer of the watch. Time shown had no effect on the ratings of the watches. Implications and limitations are considered.
\end{abstract}

\section{Keywords}

Watch, Time, Evaluation

\section{Introduction}

With both functional and stylistic attributes, the wristwatch is a product of high demand and has historically been linked to a person's identity and status (Jones \& Hafner, 2012). Watch sales are very important business and the advertising effort that accompanies it.

In February 2013, Swiss watch-making exports stood at a value of 1.6 billion Swiss Francs (1.12 billion British Pound Sterling), reflecting this market of high demand (Federation of the Swiss Watch Industry, 2013). The marketing of watches must be of considerable importance particularly in a competitive and declining market. With 365.8 million United States Dollars being spent on watch advertising in 2011 alone in the USA (Thompson, 2012), this certainly appears to be the case.

One thing watch advertisements appear to have in common is that they all tell the same time. A Google images search of the term expensive watches, Rolex, Omega, Longines or almost any other conceivable prestigious watch brand that may incur sophisticated marketing shows watch faces where the overwhelming majority have 
the hands displaying the time 1:50 or 10:10. There are many reports that confirm this. We content analysed magazines entirely dedicated to watches and confirmed that in over $90 \%$ of advertisements they showed the "smiley face" times of 1:50 or 10:10. This phenomenon can even be seen in prolific pocket watch adverts dating back to the early 1900's, such as Omega's notable advertisement highlighting its role as the Official Olympic Games timekeeper, and in almost all current watch shops.

Despite the widespread nature of this advertising strategy, little psychological literature appears to yet exist on its influence on people's preference of watches. Accordingly, the reasons for this phenomenon are left unanswered. Intuitively, one potential reason for this choice of display time on wristwatch faces is that it causes the hands to construct a shape similar to a human "smiley face", and this explanation is the focus of our experiment.

Dumitrescu (2010) in his theory of product personality argues that people assign to the product a human personality. Similarly Janlert and Stolerman (1997) argue that people and things have attributes of high-level character that help us to understand and enter into a relationship with them. There is also a literature on the anthropomorphisms in product design such as making the front of cars look like faces (Puzakova, Kwak, \& Rocereto, 2013). Thus, it may be possible that by subtly making the watch hands construct a smiley face, the wristwatch is made more human and therefore given a personality which increases consumer preference. Govers and Schoormans (2005) have suggested that people prefer products with a product personality that matches their self-image, possibly making watches pertaining the "smiley face" more desirable to people perceiving themselves as positive.

In perhaps one of the very few studies actually involving wristwatches directly, Halberstadt and Rhodes (2000) found that when rating 50 photos of wristwatches, averageness and familiarity correlated strongly with attractiveness and each other. With familiarity being identified as a predictor of perceived watch attractiveness, it is therefore also plausible that commonly seen human-like characteristics such as smiley faces increase the familiarity and attractiveness of watches. Furthermore, psychological literature has previously well established that through the mere-exposure effect people respond positively to the familiar (Bornstein, 1989), strengthening this perspective.

It may also be that smiley faces draw attention and increase approachability, with the finding that happy expressions activate left-lateralized processes in the amygdaloid region, a region associated with positive emotions and approach-related behaviour (Canli et al., 2002). It appears inferable that positivity and likeability go hand in hand, so with the elicitation of positive emotions from seeing a smiley face, watch preference could also be increased.

The most relevant study to this was that of Labroo, Dhar \& Schwarz (2008) who showed that it was possible to prime smile (10:10) and frown (8:20) watches by using positive or negative words. The positively primed people were more likely to say they liked the smiley face watch, were more likely to buy and put them in a good mood.

This study tested the hypothesis that in both male and female watches a smiley face would lead to a higher evaluation of the watch than any other time, particularly the opposite, namely 16:40 or 18:20.

\section{Method}

\subsection{Participants}

Study 1: Students. 60 participants took part in the study with a mean age of 25.3 years and the sample consisted of 29 males and 31 females. They were selected from London University. The subjects were randomly assigned to one of six conditions, with each condition having 10 participants.

Study 2: Non students. 144 participants took part in the study with a mean age of 29.9 years. The sampling type was opportunistic consisting of 69 males and 75 females' survey while waiting for trains at a busy British railway station.

\subsection{Stimuli and Apparatus}

The stimulus set for all of the experimental conditions consisted of six notably different photographs of watches taken from the internet in a full front perspective. For each condition the six watch faces ( 3 males and 3 female) were presented on a single white A4 background, measuring no more than $5 \times 7 \mathrm{~cm}$, and arranged in a $2 \times 3$ format. Each watch had no brand logo in order to prevent potential recognition biasing the judgements.

The watches either displayed the time 13:50, 9:00, 19:20, 8:10 or 10:25 (see Figure 1). The different times 

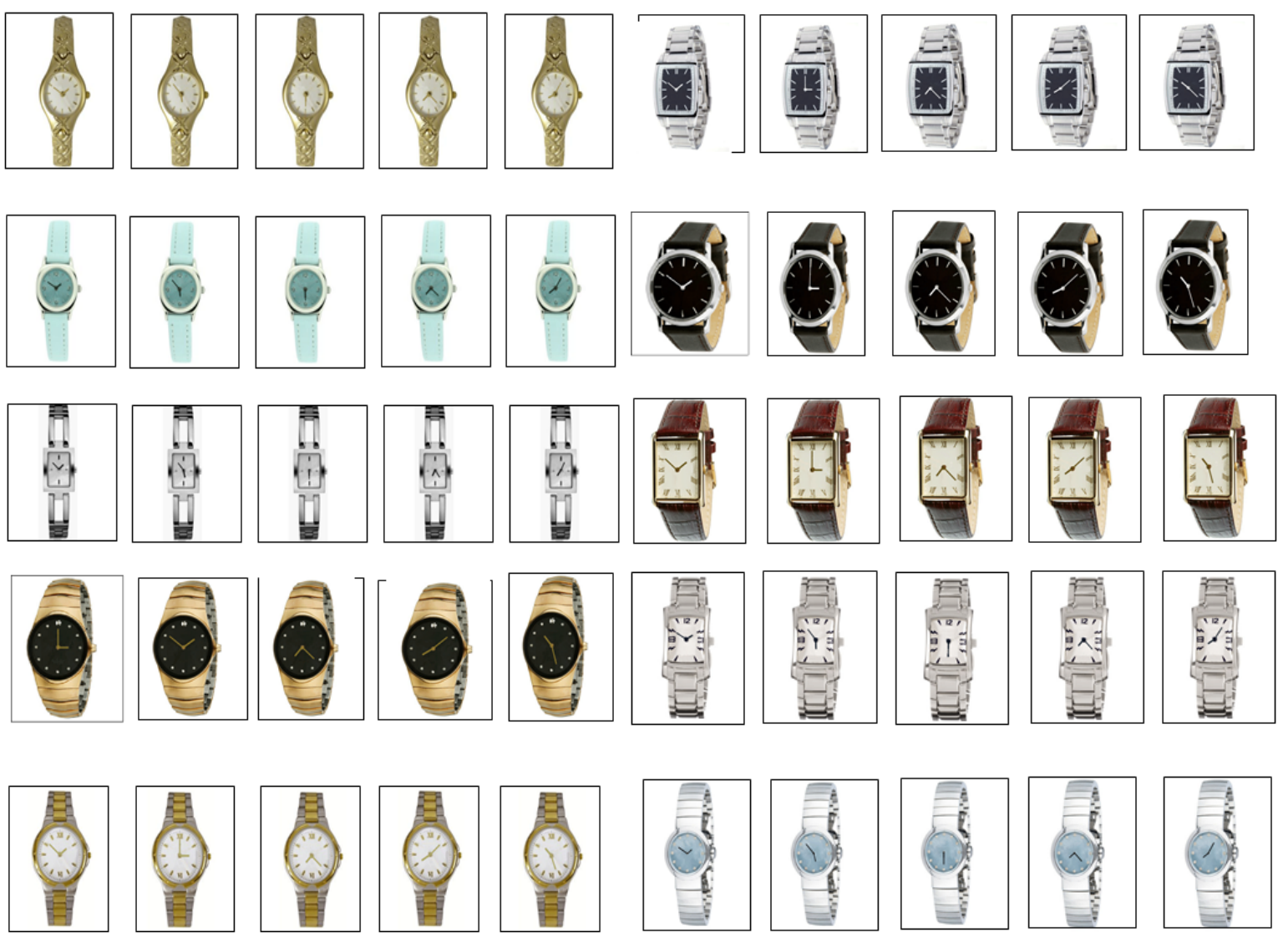

Figure 1. The stimuli used in this study.

appeared once on each watch face, and on a different watch face for each condition, so that all of the six times appeared once on each watch face across conditions. They were in conditions A to F. The times were selected to show the watch hands constructing a variety of different shapes, with 1:50 having the hands create the so called "smiley face". Accordingly, no digital watches were used. The experimental data was collected using pen and paper questionnaires and done under no time constraints.

\subsection{Procedure}

All instructions were given verbally as well as provided on the questionnaires, and the questionnaires were distributed by two researchers along with the appropriate stimulus set. The questionnaires required participants to rate each of the six watches on a scale of 1 - 10 (with 10 being the highest) on four measures; their perceived attractiveness, expensiveness, the income level of the typical wearer of the watch, and the sense of style of the typical wearer of the watch. Thus, each questionnaire required participants to give 24 ratings. The various measures were selected to attempt to cover the range of ways that people may judge watches as a consumer. The questionnaires also collected the additional information of the age, sex, country of birth and job occupation of the participants for demographics.

\section{Results and Statistical Analysis}

We used analysis of variance with planned comparisons. This allowed us to test the hypotheses.

\subsection{Study 1}

A $6 \times 6$ ANOVA was run for each of the ratings followed by planned comparisons. There was no significant effect of the time displayed on the four ratings for watch faces A, B, E and F. However, there was a significant 
effect of the time on the rating given for the measure of income level for watch face $\mathrm{C}$, and for the ratings given for the measures of expensiveness and sense of style for watch face D.

A one-way ANOVA on the ratings for watch face $D$ yielded showed ratings for expensiveness $(M=5.8)$, $F(5,54)=2.985, p<.05$, and sense of style $(M=4.6), F(5,54)=3.093, p<.05$, were found to be significantly different across conditions. A post hoc Tukey test revealed that for the ratings of expensiveness, the times 1:50 and 7:20 exclusively varied significantly at $p<.05$, as did the times 1:50 and 7:20, and 1:50 and 9:00, for ratings of sense of style.

\subsection{Study 2}

A similar analysis was computed. A one-way ANOVA revealed for all of the watch faces (A-E) there was an non-significant effect of time displayed on the ratings of all four measures (attractiveness, expensiveness, income level, and sense of style). The only comparison made, which was significant was within the post hoc Tukey test for watch B. The test results showed that the ratings of the sense of style of the wearer differed significantly between times 2 (0900) and 5 (7:20) neither of which constitutes the investigated "smiley face" watch hands.

The data were combined and the analyses re-run but as before there were no greater than chance significant findings for the different analyses.

\section{Discussion}

The results of both studies showed no rating effect for the time on the face of the watch. This is surprising as it does not explain why the use of the display time 1:50 is so indisputably pervasive.

There may however be design limitations. Due to the six different watches being presented together, it is possible that the subjects rated them in respect to each other, and rated some watches higher or lower than others due to a personal taste that was salient. Because of the necessary between-subjects design that compared the ratings within each individual watch type rather than between, this may have skewed the effect of the different times and confounded the results. Moreover, despite the lack of brand logos some participants claimed to recognise the watch manufacturer, and rated the watch accordingly, which could have further enhanced this undesirable effect.

Alternatively, there may be some other unseen explanation as to why watch manufacturers place such a heavy preference on the time of 13:50 or 10:10 for their watches in advertisements. It could be that the partiality is one based purely on aesthetics, with the hands giving the watch symmetry. It also allow for the brand name to be seen. Artistic inspection also reveals that this orientation of watch hands also frames the watch manufacturer's logo attractively, making the partiality one for increasing consumers preference for the brand rather than the watch model itself.

It may be that watch manufacturers are historically wasting their time, but otherwise the reasons behind the use of the times 10:10/13:50 and the apparent 'smiley face' in advertisements remains unseen. Being of high commercial importance to a billion pound industry, perhaps more psychological investigation into this phenomenon whilst rectifying the methodological issues outlined above will illuminate this un-researched area.

\section{Conclusion}

In this study we failed to confirm our hypotheses about the preferred time shown on watch advertisements. It may be worth replicating and extending the study to confirm this non-significant result. This still does answer the question as to why there is a clear preference for "smiley face" watch time shown in most printed advertisement for watches.

\section{References}

Bornstein, R. F. (1989). Exposure and Affect: Overview and Meta-Analysis of Research, 1968-1987. Psychological Review, 106, 265-289. http://dx.doi.org/10.1037/0033-2909.106.2.265

Canli, T., Sivers, H., Whitfield, S. L., Gotlib, I. H., \& Gabrieli, J. D. (2002). Amygdala Response to Happy Faces as a Function of Extraversion. Science, 296, 2191. http://dx.doi.org/10.1126/science.1068749 
Dumitrescu, A. (2010). A Model of Product Personality. In Proceedings of the 4th conference on European Computing Conference (pp. 88-93). Bucharest: World Scientific and Engineering Academy and Society (WSEAS).

Federation of the Swiss Watch Industry (2013). February Monthly Analysis.

Govers, P. C. M., \& Schoormans, J. P. L. (2005). Product Personality and its Influence on Consumer Preference. Journal of Consumer Marketing, 22, 189-197. http://dx.doi.org/10.1108/07363760510605308

Halberstadt, J., \& Rhodes, G. (2000). The Attractiveness of Nonface Averages: Implications for an Evolutionary Explanation of the Attractiveness of Average Faces. Psychological Science, 11, 285-289. http://dx.doi.org/10.1111/1467-9280.00257

Janlert, L. E., \& Stolerman, E. (1997). The Character of Things. Design Studies, 18, 297-314. http://dx.doi.org/10.1016/S0142-694X(97)00004-5

Jones, R., \& Hafner, C. (2012). Understanding Digital Literacies. New York: Routledge

Labroo, A., Dhar, R., \& Schwarz, N. (2008). Of Frog Wines and Frowning Watches. Journal of Consumer Research, 34, 819-831. http://dx.doi.org/10.1086/523290

Puzakova, M., Kwak, H., \& Rocereto, J. (2013) When Humanizing Brands Goes Wrong: The Detrimental Effect of Brand Anthropomorphization Amid Product Wrongdoings. Journal of Marketing, 77, 81-100. http://dx.doi.org/10.1509/jm.11.0510

Thompson, J. (2012). Million-Dollar Club: What Watch Brands Spent the Most on Advertising in 2011? WatchTime.com. 